\title{
STUDI POLA PENGELOLAAN SAMPAH B3 RUMAH TANGGA DI KABUPATEN BANJAR WILAYAH BARAT ( KECAMATAN SUNGAI TABUK, KERTAK HANYAR DAN GAMBUT )
}

\author{
Study of Households Waste Management System for Hazardous and Toxic Materials in District \\ at Banjar (Sub district at Sungai Tabuk,Kertak Hanyar and Gambut) \\ Mu'min', Andy Mizwar', Rizqi Puteri Mahyudin ${ }^{3}$ \\ Program Studi Teknik Lingkungan, Teknik Lingkungan, Universitas Lambung Mangkurat Jl. A. \\ Yani KM 36,5 Banjarbaru Kalimantan Selatan, Indonesia \\ e-mail: muminazagin20@gmail.com
}

\begin{abstract}
ABSTRAK
Penelitian ini bertujuan untuk menganalisis timbulan dan komposisi, menganalisis hubungan tingkat pendapatan dengan jumlah sampah B3 serta mengkaji kondisi eksisting pola pengelolaan sampah B3 rumah tangga di wilayah Kabupaten Banjar wilayah barat (Kecamatan Sungai Tabuk, Kertak Hanyar dan Gambut). Metode yang digunakan pada penelitian ini antara lain observasi lapangan, sampling dan wawancara. Berdasarakan hasil pengukuran diketahui timbulan sampah B3 rumah tangga di Kecamatan Sungai Tabuk, Kertak Hanyar dan Gambut sebesar 0,048 kg/orang/hari atau 1,481 liter/orang/hari. Komposisi yang paling banyak ditemukan adalah produk perawatan diri seperti pampers. Berdasarkan uji korelasi spearman, hanya komposisi produk otomotif yang berhubungan dengan tingkat pendapatan. Sedangkan pada sampah B3 rumah tangga tidak ada pola pengelolaan khusus terhadap sampah B3 rumah tangga.
\end{abstract}

Kata kunci : Timbulan, Komposisi, sampah B3

\begin{abstract}
This study discusses analyzing the generation and composition, analyzing the relationship between the level of income and waste generated of hazardous and toxic waste, assessing the existing pattern of management waste generated of hazardous and toxic waste households in the area of Banjar District in the west (Sungai Tabuk Sub District, Kertak Hanyar and Gambut). The methods used in this study include field observations, sampling and interviews. Based on the results of measurements waste generated of hazardous and toxic waste households in Sungai Tabuk Sub District, Kertak Hanyar and Gambut at $0.048 \mathrm{~kg} /$ person / day or 1.481 liters / person / day. The most found composition is self-care products such as diapers. Based on the trial speasrman, only the composition of automotive products is related to income levels. While in household hazardous and toxic waste there is no special maintenance pattern for hazardous and toxic waste.
\end{abstract}

Keywords: Waste Generated, Composition, Hazardous and Toxic Waste 


\section{PENDAHULUAN}

Kabupaten Banjar yang memiliki ibukota Martapura merupakan salah satu Kabupaten terpadat di Provinsi Kalimantan Selatan. Kabupaten Banjar memiliki jumlah penduduk 563.062 jiwa/ km² yang termasuk kategori kota besar ( BPS Kab. Banjar, 2016).Kabupaten Banjar sendiri terbagi menjadi dua wilayah yaitu wilayah barat dan timur. Wilayah barat sendiri yang terdiri dari kecamatan Sungai Tabuk, Kertak Hanyar dan Gambut memiliki jumlah penduduk 146,054 jiwa/ $\mathrm{km}^{2}$. Dari ketiga kecamatan tersebut jumlah penduduknya mengambil sepertiga dari jumlah keseluruhan penduduk Kabupaten Banjar. Penyebab kepadatan penduduk dari ketiga kecamatan ini karena letaknya yang berdampingan langsung dengan Kota Banjarmasin dan juga sebagai sarana penunjang ibukota Kalimantan Selatan yaitu Banjarmasin. Hal ini yang merupakan salah alasan mengapa titik pengambilan sampel dilakukan di ketiga kecamatan ini nantinya. Dengan tingginya kepadatan penduduk tersebut maka akan berdampak pada perkembangan kota dan pertumbuhan ekonomi yang akan memicu bertambah besarnya jumlah timbulan dan komposisi sampah yang dihasilkan.

Melihat pada sifat- sifat sampah B3, karakteristik dan akibat yang ditimbulkan pada masa sekarang maupun pada masa yang akan datang diperlukan langkah pencegahan, penanggulangan dan pengelolaan (Ginting, 2007). Maka dari itu penelitian tentang sampah B3 rumah tangga ini dilakukan untuk mengetahui jumlah timbulan dan komposisi sampah dan karakteristik sampah di Kabupaten Banjar agar dapat mengatasi permasalahan lingkungan dan juga untuk perencanaan, pengelolaan sampah di Kabupaten Banjar guna untuk mendukung pembangunan Kota Martapura Kabupaten Banjar.

Penelitian ini bertujuan untuk menganalisis timbulan dan komposisi, menganalisis hubungan tingkat pendapatan dengan jumlah sampah B3 serta mengkaji kondisi eksisting pola pengelolaan sampah B3 rumah tangga di wilayah Kabupaten Banjar wilayah barat (Kecamatan Sungai Tabuk, Kertak Hanyar dan Gambut).

\section{METODE PENELITIAN}

\subsection{Lokasi Penelitian}

Lokasi penelitian ini dilakukan di kabupaten banjar wilayah barat khususnya di Kecamatan Kecamatan Sungai Tabuk, Kertak hanyar dan Gambut.

\subsection{Alat dan Bahan}

Alat yang digunakan dalam penelitian ini adalah kotak ukur volume, timbangan digital, thrash bag, alat ukur jarak dan alat pelindung diri.

\subsection{Pengumpulan Data}

Data yang dikumpulkan meliputi data primer berupa jumlah timbulan sampah B3 rumah tangga, komposisi sampah B3 rumah tangga dan kondisi eksisting. Sedangkan data sekunder berupa data jumlah penduduk dan data jumlah kelurahan.

\subsection{Metode Pengolahan Data}

Data yang diperoleh disajikan dalam bentuk tabel dan grafik, juga menggunakan pembahasan secara deskriptif. Data jumlah timbulan dan komposisi dilakukan sesuai tata cara pengambilan dan pengukuran contoh timbulan dan komposisi sampah perkotaan SNI Nomor 19-3964-1994. 
Penelitian ini dilakukan selama 8 hari. Sedangakan untuk mengetahui kondisi eksisting dan hubungan tingkat pendapatan dengan jumlah sampah B3 rumah tangga dilakukan secara observasi, ditambah wawancara terhadap masyarakat, petugas kebersihan, pegawi Dinas LH dan PUPR Kabupaten Banjar.

\section{HASIL DAN PEMBAHASAN}

\subsection{Timbulan dan Komposisi Sampah B3 Rumah Tangga}

Timbulan sampah B3 rumah tangga adalah berat sampah atau volume sampah yang dihasilkan dari sumber sampah B3 rumah tangga dalam suatu wilayah tertentu per satuan waktu (Ruslinda dan Yustisia, 2013). Hasil pengukuran timbulan sampah B3 berdasarkan tingkat pendapatan yang dilakukan pada wilayah barat Kabupaten Banjar ( Sungai Tabuk, Kertak Hanyar dan Gambut) dapat dilihat pada Tabel 1 berikut ini:

Tabel 1 Timbulan Sampah B3 Rumah Tangga di Kabupaten Banjar Wilayah Barat

\begin{tabular}{lccc}
\hline \multicolumn{1}{c}{ Tingkat Pendapatan } & $\begin{array}{c}\text { Timbulan } \\
\text { (kg/orang/hari) }\end{array}$ & $\begin{array}{c}\text { Timbulan } \\
\text { (L/orang/hari) }\end{array}$ & Densitas (Kg/L) \\
\hline Pendapatan Tinggi & 0,068 & 1,711 & 0,038 \\
Pendapatan Sedang & 0,038 & 1,460 & 0,026 \\
Pendapatan Rendah & 0,037 & 1,273 & 0,025 \\
Rata- rata & 0,048 & 1,481 & 0,030 \\
\hline
\end{tabular}

Hasil perhitungan timbulan sampah B3 rumah tangga berdasarkan tingkat pendapatan pada Kabupaten Banjar wilayah Barat sebesar $0,048 \mathrm{~kg} /$ orang/hari atau 1,481 liter/orang/hari. Jumlah timbulan tersebut lebih tinggi dibandingkan dengan wilayah Kecamatan Gayungan, Surabaya sebesar 0,002 kg/orang/hari (Trihadiningrum, 2014), Kabupaten Sleman dengan jumlah timbulan sampah B3 sebesar 0,002 kg/orang/hari (Iswanto, 2016), Kecamatan Tamalate Kota Makassar dengan timbulan sebesar 0,0003 kg/orang/hari (Rahim dan Mustari, 2013). Dalam Penelitian yang dilakukan (Zulfah, 2017) di Kabupaten Hulu Sungai Selatan yang berbatasan di sebelah utara lokasi penelitian ini, hasil jumlah timbulan sampah B3 yang dihasilkan tidak jauh berbeda yaitu sebesar 0,038 kg/orang/hari dan 0,099 kg/orang/hari.

Jumlah timbulan sampah B3 rumah tangga yang dihasilkan tidak sejalan dengan pendapat Damanhuri $\left(2010_{\mathrm{A}}\right)$ yang menyatakan bahwa timbulan sampah B3 rumah tangga $\pm 2 \%$ dari sampah domestik yang dihasilkan setiap orang perhari. Persentase timbulan sampah B3 yang tinggi kemungkinan disebabkan penambahan karakteristik infeksius yang berupa produk pampers dan pembalut.. Hal ini sesuai dengan penelitian yang dilakukan oleh (Zulfah, 2017) tentang kebanyakan responden yang masih memiliki anak kecil. Apabila karakteristik infeksius dihilangkan maka timbulan sampah B3 rumah tangga wilayah Barat Kabupaten Banjar yaitu sebesar 0,019 Kg/orang/hari dengan persentase timbulan sampah B3 rumah tangga terhadap sampah domestik yang dihasilkan sebesar 4,42\%. Persentase ini hampir sama dengan yang dilakukan (Agustina, 2018) di wilayah Kecamatan Martapura Kabupaten Banjar yaitu sebesar 4,09\%, dan persentase ini masih tinggi dibandingkan dengan wilayah lain seperti Kabupaten Hulu Sungai Selatan sebesar 2,57\% (Zulfah, 2017) dan Kota Padang Sebesar 1,09\% (Ruslinda dan Yustisia, 2012). 
Komposisi sampah B3 rumah tangga dengan produk pampers akan disajikan pada Gambar 1 dan komposisi sampah B3 rumah tangga tanpa produk pampers pada Gambar 2

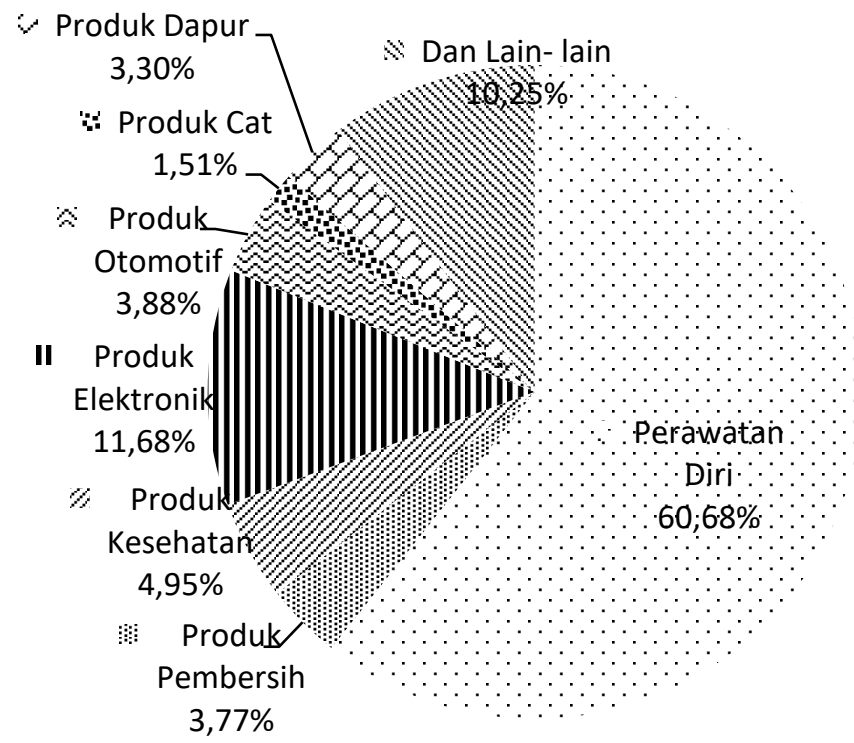

Gambar 1 Komposisi Sampah B3 Rumah Tangga dengan Produk Pampers

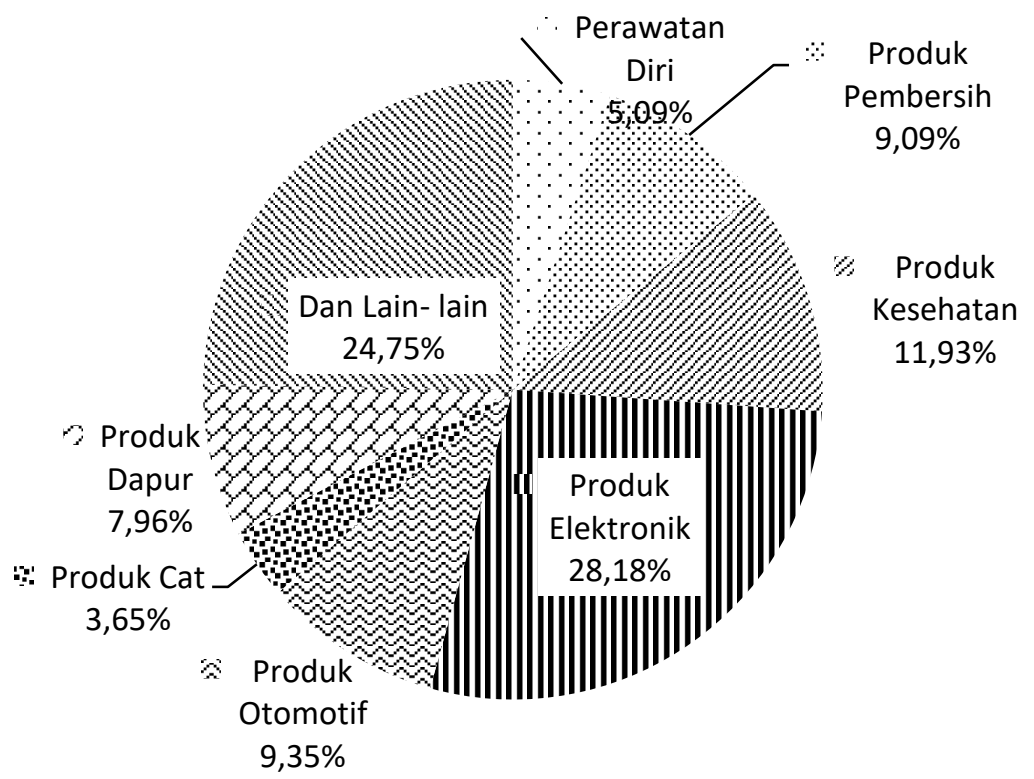

Gambar 1 Komposisi Sampah B3 Rumah Tangga Tanpa Produk Pampers

Dari Gambar 1 dapat dilihat bahwa komposisi sampah B3 rumah tangga Wilayah Barat Kabupaten Banjar secara kesueluruhan berdasarkan jenis penggunaannya produk perawatan diri merupakan komposisi yang paling mendominasi pada wilayah sampling yang mencapai $60,68 \%$ dari total sampah B3 yang diukur. Hasil penelitian ini sama dengan yang dilakukan (Agustina, 2018) dan (Zulfah,2017), yang mana sampah B3 didominasi oleh produk perawatan diri. Komposisi yang ditemukan yaitu berupa pampers, pembalut wanita, kemasan minyak rambut, 
kemasan pasta gigi, botol parfum bekas, bekas kemasan sampo, kosmetik kadaluarsa, kemasan deodorant dan sisa kemasan obat kadaluarsa. Komposisi yang mendominasi pada produk perawatan diri ada pampers. Hal ini menunjukkan kebanyakan masyarakat kalangan menengah ke atas yang di jadikan responden masih memiliki anak kecil.

Produk yang menempati urutan kedua paling banyak ditemukan yaitu Produk elektronik seperti lampe bekas, baterai bekas, catridge, dan kabel cas handphone bekas. Komposisi yang mendominasi adalah lampu bekas dan kabel cas handphone bekas. Kondisi ini terjadi karena masyarakat mengikuti perkembangan teknologi yang semakin meningkat sehingga masyarakat tidak membuang kabel cas handphone yang sudah rusak melainkan mereka kumpulkan dan disimpan begitu saja. Dan pada saat pengambilan sampe dilapangan, kabel cas handphone dan lampu bekas menjadi sampah B3 rumah tangga yang paling banyak ditemukan untuk produk elektronik.

Kemudian produk yang banyak ditemukan adalah produk kesehatan dengan komposisi yang berupa sisa kemasan/obat kadaluarsa, sisa obat nyamuk bakar dan perban. Hal ini menunjukkan banyaknya sisa kemasan/ obat kadaluarsa karena pada saat pengambilan sampel dilapangan terjadi pada saat musim hujan dan bisa saja pada musim hujan yang menyebabkan banyaknya sisa kemasan obat yang dikonsumsi untuk mencegah masyarakat agar terhindar dari penyakit. Berbeda dengan produk cat komponen- komponen yang ditemukan adalah cairan thiner, kaleng cat semprot, dan kaleng cat juga banyak ditemukan.

Komposisi sampah B3 rumah tangga pada produk pembersih ditemukan dengan beraneka ragam bentuk seperti kemasan detergen, sabun cuci piring, botol pembersih lantai, sisa kemasan pemutih pakaian dan kaleng pengkilap sepatu. Komposisi yang mendominasi adalah sisa kemasan detergen. Hal ini karena adanya pengaruh pola hidup masyarakat sehari hari dengan komposisi sampah yang mereka hasilkan.Pada dasarnya masyarakat lebih cenderung membeli keperluan rumah tangga seperti kemasan detergen kecil atau sachet di kios-kios terdekat selain harga murah dan juga cepat habis digunakan. Hal ini yang memicu jumlah timbulan menjadi lebih banyak.

\subsection{Hubungan Tingkat Pendapatan dengan Jumlah Sampah Perkomposisi}

Berdasarkan hasi uji korelasi Spearman, untuk Produk perawatan diri, produk pembersih, produk kesehatan, produk cat, produk dapur dan produk lainnya menunjukkan nilai korelasi yang lemah dan sangat lemah sehingga nila-nilai tersebut menandakan hubungan yang rendah antara tingkat pendapatan dengan jumlah sampah B3 rumah tangga perkomposisi. Spearman correlation yang bernilai positif artinya semakin tinggi pendapatan, maka semakin banyak jumlah produk yang dihasilkan dan jika Spearman correlation yang bernilai negatif menandakan bahwa semakin tingii pendapata, maka semakin rendah produk yang dihasilkan atau sebaliknya. Dan untuk nilai Sig. (2tailed) dari produk perawatan diri, produk pembersih, produk kesehatan, produk cat, produk dapur dan produk lainnya menunjukkan nilai $>0,05$ maka dapat disimpulkan bahwa tidak ada hubungan yang signifikan dengan jumlah sampah B3 rumah tangga perkomposisi.

Sedangkan pada produk otomotif dengan nilai korelasi 0,412 dan signifikasi $<0,05$ jadi $\mathrm{H}_{\mathrm{o}}$ ditolak. Hal ini berarti terdapat hubungan yang signifikan antara pendapatan dengan komposisi. Pada produk otomotif menandakan bahwa semakin tinggi pendapatan, maka semakin tinggi komposisi sampah yang dihasilkan. Hal ini sesuai dengan yang disebutkan (Ramandhani, 2011) bahwa tingkat ekonomi tinggi umumnya menghasilkan sampah anorganik lebih banyak dibandingkan dengan tingkat ekonomi rendah. 


\subsection{Kondisi Eksisting Pola Pengelolaan Sampah B3 rumah tangga di Kabupaten Banjar Wilayah Barat}

Penelitian yang dilakukan terhadap 48 warga yang dianggap sebagai responden dinilai mampu mewakili karakteristik umum sosial ekonomi masyarakat kabupaten Banjar di wilayah barat. Karakteristik yang meliputi jenis kelamin, usia, pendidikan, pekerjaan pendapatan dan jumlah penghuni tiap rumah yang dijadikan sampel penelitian.

Pada saat interview, responden didominasi oleh oleh perempuan sebanyak 58\% dan sisanya $42 \%$ terdiri dari laki-laki. Hal karena pada waktu interview dilakukan pada siang hari sampai menjelang sore, dan dimana pada waktu siang hari banyak di jumpai responden perempuan dan responden laki- laki pada saat sore hari ketika kepala keluarga baru pulang kerja. Faktor penyebab lainnya yaitu kebanyakan perempuan berperan aktif dalam mengelola rumah tangga. Pada Tabel 2 akan menunjukkan persentase perilaku masyarakat dalam mengelola sampah B3 rumah tangga yang mereka hasilkan.

Tabel 2. Perilaku masyarakat dalam mengelola sampah B3 rumah tangga

\begin{tabular}{ll}
\hline Aspek Perilaku & Keterangan \\
\hline Pengetahuan & $\begin{array}{l}94 \% \text { tidak memiliki pengetahuan tentang sampah B4 rumah } \\
\text { tangga }\end{array}$ \\
Penggunaan produk B3 & $\begin{array}{l}100 \% \text { selalu menggunakan produk-produk berbahan B3 } \\
98 \% \text { tidak melakukan pemilahan }\end{array}$ \\
Pemilahan & $100 \%$ dari bahan plastik \\
Pewadahan & $58 \%$ tidak membuang sampah ke TPS \\
Membuang sampah ke TPS &
\end{tabular}

Berdasarkan hasil interview kepada Kepala Bidang Pengelolaan Sampah, Pertamanan dan Limbah menyatakan bahwa penanganan pengelolaan sampah B3 sudah mulai direalisasikan dari sumber, dimana pemerintah daerah sudah melakukan sosialiasi ke desa/kelurahan agar masyarakat melakukan pemilahan dari sumber. Sosialisasi dilakukan lengkap dengan mengajak masyarakat mengumpulkan sampah B3 rumah tangga yang akan dibuang, dan ketika sudah terkumpul maka akan diangkut menggunakan truk khusus pengangkut sampah B3 yang telah disediakan.

Tidak ada penangananan khusus untuk Sampah B3 rumah tangga Kabupaten Banjar Wilayah Barat yang dilakukan pemerintah. Pemerintah hanya menyediakan TPS 3R di desa/kelurahan, dimana pengelolaan sampah B3 rumah tangga di TPS 3R sendiri ikut tercampur dengan sampah domestik. Pengelolaan sampah untuk kegiatan pemilahan bertujuan mengurangi jumlah timbulan dan dampak di tempat pemrosesan akhir (TPA). Pemilahan dilakukan oleh petugas TPS 3R setempat hanya berdasarkan komposisi sampah domestik, tidak ada pemilahan khusus untuk sampah B3 rumah tangga. Adapun alur pola pengelolaan sampah B3 rumah tangga di Kabupaten Banjar Wilayah Barat sebagai berikut : 


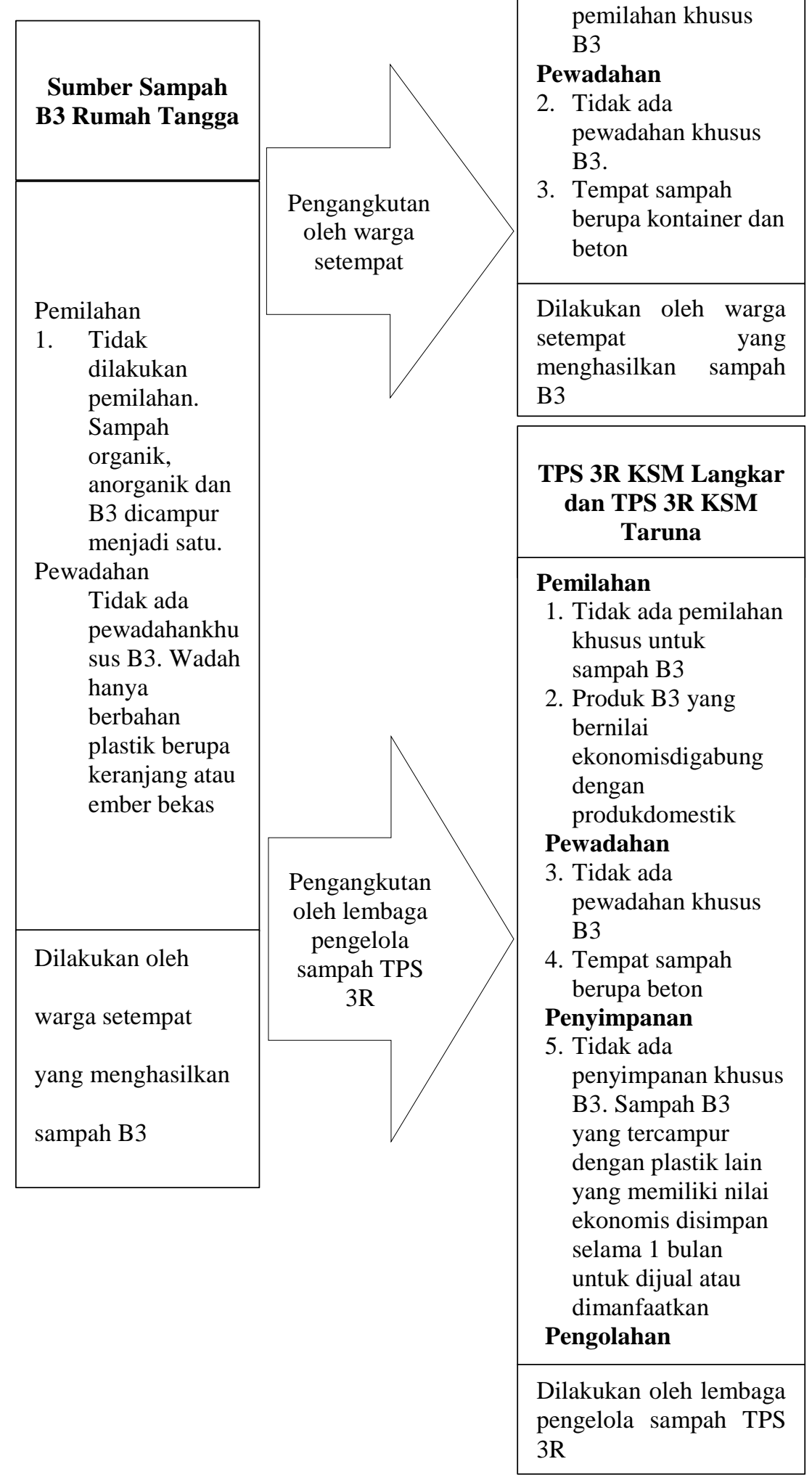

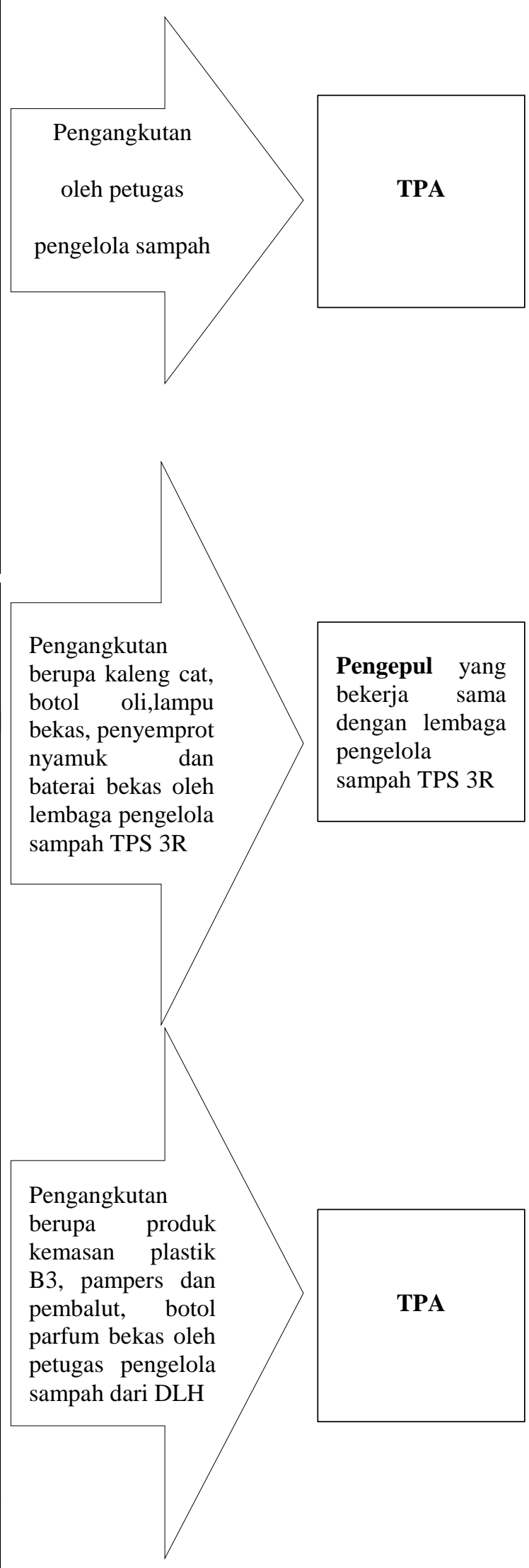

Gambar 1. Diagram Alur Pola Pengelolaan Sampah B3 di Kabupaten Banjar Wilayah Barat 


\section{KESIMPULAN}

Berdasarkan hasil penelitian Tugas Akhir tentang studi pola pengelolaan sampah B3 rumah tangga di Kabupaten Banjar Wilayah Barat (Kecamatan Sungai tabuk, Kertak hanyar dan Gambut) dapat diambil kesimpulan sebagai berikut :

1. Timbulan sampah B3 rumah tangga di Kabupaten Banjar Wilayah Barat adalah 0,048 $\mathrm{kg} /$ orang/hari atau 1,481 liter/orang/hari. Dan komposisi sampah B3 rumah tangga yang paling banyak ditemukan adalah produk perawatan diri yang berupa pampers.

2. Berdasarkan uji korelasi spearman diketahui bahwa hanya komposisi produk otomotif yang berhubungan dengan tingkat pendapatan, sedangkan produk-produk yang lainnya tidak terdapat hubungan antara tingkat pendapatan masyarakat dengan jumlah sampah B3 perkomposisi.

3. Pola pengelolaan sampah B3 rumah tangga di Kabupaten Banjar Wilayah Barat adalah tidak ada pengelolaan khusus terhadap sampah B3 rumah tangga.

\section{DAFTAR PUSTAKA}

BPS. 2016. Kabupaten Banjar Dalam Angka. Badan Pusat Statistik Kabupaten Banjar. Kabupaten Banjar.

Damanhuri, E. (2010A). Pengelolaan Bahan Berbahaya dan Beracun (B3). Diktat Kuliah Tl-3204. Program Studi Teknik Lingkungan, Fakultas Teknik Sipil dan Lingkungan, Institut Teknologi Bandung

Ginting, Perdana. (2007). Sistem Pengelolaan Lingkungan dan Limbah. Yrama Widya, Bandung Standart Nasional Indonesia Nomor SNI-03-3242-1994 tentang Tata Cara Pengelolaan Sampah di Permukiman, Badan Standar Nasional ( BSN ).

Rahim, I. R. dan Mustari, A, S. (2013). Studi Pengelolaan Sampah B3 Rumah tangga di Kelurahan Mangasa Kecamatan Tamalate Kota Makassar.

Ruslinda, Y. dan Yustisia, D. (2013). Analisis Timbulan dan Komposisi Sampah Bahan Berbahaya dan Beracun (B3) Rumah tangga Di Kota Padang Berdasarkan Tingkat Pendapatan. Jurnal Teknik Lingkungan UNAND. Vol. 9 No. 2, Januari 2012. Halaman 1-12

SNI 19-3964-1994 Tentang Metode Pengambilan Dan Pengukuran Contoh Timbulan Dan Komposisi Sampah Perkotaan.

Trihadiningrum, Y. dan Sukanto. (2014). Studi Pengelolaan Sampah B3 Permukiman di Kecamatan Gayungan Surabaya

Zulfah, Khairina. (2017). Studi Pola Pengelolaan Sampah B3 Rumah Tangga Kabupaten Hulu Sungai Selatan. Jurusan Teknik Lingkungan. Fakultas Teknik 